\title{
Students' Learning Experiences in the Foundation Year of a Sino-Foreign Joint University
}

\author{
Yimiao Chen
}

\author{
School of Education and English, University of Nottingham, Ningbo, Zhejiang, 315000, China \\ Corresponding author.Email: biyyc16@nottingham.edu.cn
}

\begin{abstract}
Transnational higher education (THHE) has developed rapidly in China. Over the past decade, its latest form, namely, cooperation universities have been established, which may lead the future development of TNHE. Considering studies on this type of institution are very limited, this research adopted a case study approach to examine students' teaching and learning experiences in a joint university. It mainly focuses on the teaching outcomes of the preliminary year to see how this period helps and what academic difficulties are left to students. Using the intercultural dialogue framework' to frame the study, 6 one-to-one semi-structured interviews were done. The emphasis was put on curriculum design, teaching and learning approaches and assessment styles. The findings reveal the necessity to have the foundation year, which promotes students better transition into undergraduate degree courses. However, the academic challenges mentioned by learners also reveal that this stage should be strategically designed to achieve effective teaching and learning. Moreover, some vital implications are yielded for boosting the mutual understanding between course providers and students from academic and cultural aspects.
\end{abstract}

Keywords: Transnational higher education, joint university, China, teaching and learning, students' experiences

\section{INTRODUCTION}

Transnational Higher Education (TNHE) in China refers to Chinese and foreign education institutions cooperate to establish joint programs or institutions in China [1]. Although TNHE has developed rapidly over the past decade, there is still concern about its sustainability for which is considered as a second choice, compared with domestic and overseas higher education [2]. As mentioned by [3], the learning experiences of students is the principal factor affecting their satisfaction and achievement, and even the reputation of their school. Hence, if TNHE would like to remain competitive in the higher education market in China, it is vital to understand and improve students' learning experiences. Nevertheless, previous studies mainly researched the academic experiences of international students, only very few focused on joint programs [3]. Furthermore, nearly no research specifically examined joint universities from the perspective of students' experiences. Unlike cooperation programs, this type of university is not affiliated to a certain institution in China. It is given more autonomy in various aspects, such as, in teaching and management, meaning there is more room for development [4]. Therefore, it could play an exemplary role in leading the way for the progress of TNHE [5], and then leading China to meet the international standards of higher education [6]. As a result, researching joint universities will not only provide a direction for the future development of TNHE, but also offer insights to administrators and teachers into the innovation of the education system in China.

To be specific, students' experiences during the first stage of cooperation universities will be investigated. Considering TNHE is characterized by allowing students to receive foreign or partly foreign education in their homeland [7], to better adapt to overseas undergraduate courses, students need time to prepare themselves in terms of language and academic culture. Therefore, this essay intends to demonstrate the teaching achievements of the preparation stage, thus determining how well students have been prepared for subsequent study. In addition, the academic challenges they encountered throughout the whole learning process and the underlying reasons behind that will also be examined. 


\section{LITERATURE REVIEW}

\subsection{TNHE in China}

Transnational higher education is developing fast in China, as shown in Figure 1, which implies that it has become an essential part of the Chinese HE system. Though there are three cooperation types, the latest and most prominent one is joint universities, which aim to introduce foreign high-quality educational resources into China, thereby promoting the reform and development of domestic higher education [8]). Normally the foreign partner is responsible for providing intellectual property, for example, the curriculum, pedagogy and other academic matters [9]. Nevertheless, students who study in TNHE may encounter some academic challenges. One the one hand, the instructional language in cooperation institutions is
English or mainly English. However, most Chinese students do not meet the minimum requirement to enter a foreign degree program, though they have spent 12 years learning English before they enter university [10]. As a result, the preparation stage exists to offers courses, such as English for Academic Purposes (in the following paper, the author will use EAP to replace English for Academic Purposes), which develop students' academic English skills to help them better adapt to subsequent undergraduate studies. On the other hand, as culture distinguishes one nation from another, it is the key element that determines whether an international business can succeed, including TNHE [10]. Therefore, the comprehension of foreign academic culture should also be emphasized when conduct TNHE, which may affect the conduct and development of TNHE [11].

Table 1. The number of TNHE programs and institutions in China [12]

\begin{tabular}{|l|l|l|l|}
\hline $\begin{array}{l}\text { Cooperation } \\
\text { type }\end{array}$ & $\begin{array}{l}\text { Sino-foreign cooperation } \\
\text { programs }\end{array}$ & $\begin{array}{l}\text { Sino-foreign cooperation } \\
\text { second-tier colleges }\end{array}$ & $\begin{array}{l}\text { Sino-foreign cooperation } \\
\text { universities }\end{array}$ \\
\hline Number & 1050 & 52 & 8 \\
\hline
\end{tabular}

When researching students' voices in the TNHE setting, most previous studies compared their experiences in China and foreign country to assess how they have been academically prepared in their homeland. [13] has done qualitative research to examine twenty Chinese students' learning experiences in a $2+2$ TNHE program. Contextual differences between China and Australia, as well as the obstacles learners met when they went overseas have been reported. Also, [3] explored the gap between two education systems, which brought a difficult adjustment to students. However, there is a lack of the detailed teaching styles and approaches adopted in TNHE programs from students' perspectives, which requires specifying. Furthermore, students' experiences of teaching and learning in joint universities remain blank. As a result, this paper fills the research gap by focusing on students in a cooperation university in China to investigate their learning experiences, thereby showing how they have been academically prepared for undergraduate study.

\subsection{Theoretical framework}

Despite the prosperity of TNHE in China, there is still much controversy about its future development. Generally 'effective teaching' can be interpreted as teaching that pays attention to students and their study [14]. However, within the TNHE context, it is more complex and requires considering more elements, including people, cultures, contexts and modes of teaching [3]. As a result, to gain comprehensive understanding of whether TNHE achieve effective teaching, students' learning experiences will be investigated. Because the intercultural dialogue (ICD) framework for transnational teaching and learning [15] offers a way to explore the perceptions and experiences of learners, it will be adopted for this research. It is comprised of five aspects: understanding of learners and contexts, culturally sensitive pedagogy, culturally contextualized curriculum, context-specific assessment and supportive learning environment. They will be presented and detailed below:

Understanding of learners and contexts indicates that students' characteristics should be considered, including their previous learning experiences, linguistic and cultural backgrounds. For example, in terms of the student-teacher relationship, Chinese students are asked to respect teachers and regard them as the authority, so they are less likely to question their teachers [16]. Also, since the order is emphasized in the class, students usually keep quiet to listen to the teachers [17]. Hence, when conducting TNHE in China, the comprehension of Chinese students should be enhanced.

A culturally sensitive pedagogy suggests the pedagogy should take students' cultural backgrounds into account, namely their beliefs and assumptions. This asks the teachers to get to know more about students from a cultural perspective. Additionally, a contextualized curriculum implies to incorporate context-based materials into the curriculum design. As mentioned by [9], courses and modules in sino-foreign joint universities do not have to be identical as the host university, part of which can be tailored to the context, as long as the core content and learning outcomes are the same. 
The next component, context-specific assessment encourages to design learner-centered assessments. In other words, the assessment style should correspond to students' features. Finally, a supportive learning environment is essential for the progress of TNHE. It indicates that both teachers and students should take efforts to achieve effective and efficient teaching and learning. To be more specific, teachers provide a safe and inclusive environment to create opportunities for learners to express themselves while students have more participation in class.

\section{METHODOLOGY}

\subsection{Context}

The research site was a sino-foreign joint university, where the graduates would be awarded the same degree certificates as those study in its foreign partner institution. The teaching model is either $2+2$ or $4+0$, meaning students can choose to take two years in China and then progress to the foreign partner institution for another 2 years or spend 4 years studying at this joint university. the foreign partner takes responsibility for all the academic matters to ensure that the curriculum, pedagogy, standards and quality are equivalent to the foreign university. To achieve this, most of the teaching staff are imported from the foreign institution. In this case, students can receive high-quality overseas higher education without going abroad. However, due to the differences between Chinese and foreign education systems, the foundation year is created, which consists of two types of courses, English for Academic Purposes (EAP) and academic content modules. It is supposed that students can be prepared fully for their degree program, both linguistically and academically after this year.

\subsection{Methods for data collection}

To explore students' in-depth study experiences in the joint institution, a case study approach was adopted, using qualitative, semi-structured interviews [18]. Considering the focus is on the foundation year (Year 1) to see how this year helps in subsequent studies, participants should have experienced both the preliminary year and undergraduate degree courses. As a result, 6 students who have finished their year 2 were chosen to examine their learning perceptions and experiences in the cooperation university. Half of them majored in science and engineering, and the other half in social sciences. In this way, it is more likely to gain perspectives from different angles. The interviews were conducted in Chinese for convenience of communication, which were recorded, transcribed and then translated into English. Of the 6 participants, 3 were male and 3 were female.
In addition to the study progress of the interviewee, English proficiency will also have an impact on the result of the interview. However, in order to ensure the normal progress of teaching, such universities usually have certain requirements for the English scores of the college entrance examination when enrolling students. Therefore, the interviewee's English proficiency can be regarded as almost the same.

\subsection{Research questions}

- Based on students' perceptions and experiences, what does the preliminary year modules help in subsequent undergraduate degree courses?

- After two years studying at this university, what academic difficulties have students encountered? and for what reasons?

\section{FINDINGS}

According to the data collected from semi-structured interviews, the findings have been divided into three themes, namely, curriculum design, teaching and learning approaches, and assessment styles. Each participant was given a serial number to protect privacy.

\subsection{Curriculum design}

Five out of six students mentioned that the EAP courses did not help improve their listening and speaking skills, one main reason is that the way it delivered and assessed has some problems:

In listening class, teachers only teach how to take notes while listening to the lecture, after which they play an audio file and then check the answers. As for exams, students just need to listen and fill in the blanks, which does not ask for understanding. (S-01)

It seems that the lessons are not supportive for undergraduate degree courses, which require students to comprehend the lecture content and catch keywords on their own. Apart from listening courses, the speaking ones are also problematic:

\section{Most learners are non-native English speakers and, more importantly, they are Chinese, who are good at exams and memorization. Hence, when the oral exam asks students to make a presentation, most of them achieve it through recitation. (S-03)}

In this way, students still cannot improve their English communication skills, which causes difficulties for future study as the interaction with teachers is rather significant. Also, half of the participants reported another problem related to listening and speaking: 
In Y1, both the teachers' spoken English and the audios we listened to are standard, either American or British accent. However, after the transition into Year 2, there are teachers with various accents, some of which are rather difficult to understand. (S-05)

As a result, without getting exposure to various accents before, students need time to adjust to them, for which influences their comprehension of lectures and hinders their communication with tutors.

In terms of reading and writing courses, massive reading materials and training in academic writing prepare students for subsequent courses. Nevertheless, some considered these modules as superficial. "It mainly teaches writing norms, such as what words cannot be used, which are not that essential (S-04)".

Moreover, learners' perception of EAP courses does not in accordance with its original purpose. They treat this kind of lesson as a high school English class, so they use the same methods to learn and believe it will be assessed the same way. As one student illuminated:

According to my previous English learning experiences, I thought the more advanced the vocabulary and the more complex the grammar, the better the writing. However, until finished $Y 2$, I have realized that the core of academic writing is to explain complex ideas in the clear and correct language. (S-02)

It seems that there are some misunderstanding when students learn academic writing as well as other course contents in Y1. The EAP lessons not only aim to improve English language proficiency but also practice students' key academic skills, which will be essential for future study. Without recognizing the significance of EAP, students may find it annoying because they have already learnt English for a long time. For instance, one participant complained 'the foundation year is so boring and ineffective because it takes most of the time to teach English'(S-04).

In addition to EAP lessons, academic content modules introduce some key academic skills, such as critical thinking, as well as subject-related knowledge. Overall, most students show a positive attitude towards these courses "I got to know the concept of critical thinking and then applied it to my daily life (S-03)". "I enjoyed studying courses related to my major, which are more useful (S-06)".

\subsection{Teaching and learning approaches}

The majority of students believed that being familiar with the western teaching pattern in Year 1 is helpful for future study because afterwards they require to be more independent to cope with tougher learning tasks.
Nevertheless, two students found the teaching mode hard to adapt to because:

Teachers only tell us what we need to learn and how to learn, then they leave us alone. Being a person without self-control, I cannot pay attention to study as I used to, resulting in a waste of time. (S-06)

Also, the lecture-seminar combined model is presented to students in the preliminary year. Considering the seminar is small-class teaching, it offers more opportunities for students to interact with their peers and teachers. The student who fancies this class model said: "with the relaxing classroom atmosphere and the friendly teachers who usually encourage learners to engage, seminars are so helpful in exchanging ideas and solving problems.'(S-03) Nevertheless, it is not easy for Chinese students to express their ideas freely because they used to be quiet and listen to the teacher passively in class. As a result, when the teacher asks a question, "Only a few students take the initiative to answer questions, while the others normally keep silent (S-02) ". "Sometimes, no one replies, so teachers choose to call students' names to let them answer (S-04)“

From these phenomena, though chances have been created to allow more interactions in seminars, the reality does not meet the expectation. In contrast, students still maintain their prior learning styles because "Most of my classmates are from China, so it is normal if I remain silent in class as almost everyone acts the same (S-06)". "I am accustomed to traditional Chinese teacher-centered approach, so I would like to listen and directly receive knowledge from the tutors $(S-05) "$.

Affected by Chinese teaching and learning approaches, learners find it hard to have more participation in class. As a result, due to limited student-teacher interaction, the effective teaching is far more to realize.

\subsection{Assessment styles}

In the foundation year, students are exposed to different assessment formats. Instead of traditional exams, diversified assessment modes have been practiced in the first year modules, including essays, presentations and group work. For instance, when asked to write an essay, teachers give step by step instructions, such as, how to make an essay plan and how to write an introduction part. Here is one student's comment:

"At first, I have no idea how to deal with the assessments. With the teachers' help, I gradually know and become familiar with the whole preparation process. (S-01)"

By this means, learners have been prepared to cope with future assessments. However, they encounter 
several challenges when the second year begins. The issue most frequently mentioned is the unclarity of scoring standards.

Unlike the foundation year, when we can receive staged feedback from instructors and then polish our assignments, in Y2, teachers only offer little information, meaning we have to take the initiative to ask for further details. (S-05)

As a result, communication with teachers is vital for which allows students to check their understanding and know more about the marking criteria. In the preceding section, a lack of interaction between teachers and students in class is found. Likewise, even after class, learners still meet communication problems

The idea of teachers being considered as the authority has been rooted in my mind since the day I went to school. Therefore, I am always afraid of them and fear to communicate with them. (S-03)

Although emails are not so efficient as face-to-face communication, I still prefer to send emails because of my poor English speaking skills, which prevents me to express my ideas clearly and fluently. (S-04)

In general, despite learners have experienced various types of assessment formats in the preliminary year, they still encounter some academic challenges because they are not able to communicate smoothly with teachers.

\section{DISCUSSION}

The findings of this study examine teaching outcomes during the first stage in the cooperation university based on students' learning experiences. To discuss what the foundation year helps in subsequent degree courses, as well as the academic challenges it brought, three themes emerge, which seem separate, but are intertwined in essence.

First of all, the curriculum design of the preliminary year has taken students' linguistic background into consideration. To be specific, EAP courses are created to develop non-native English speakers' academic English skills in terms of speaking, listening, reading and writing. In particular, listening and oral skills are highlighted for which have been ignored in English language teaching in China, but may affect students' academic performances in the joint university, where the instructional language is English [10]. However, it seems that the object of the courses has not been accomplished because the teaching and exam contents mislead Chinese learners to put their emphasis elsewhere. Facing this problem, the understanding of learners [15] should be boosted, suggesting to create opportunities for teachers to comprehend what learners need and lack. For example, before formal lessons start, designing exams and questionnaires to test students' English language skills and explore their prior learning styles. Apart from the linguistic background, a contextualized curriculum in ICD framework [15] suggests to focus on learners' previous experiences and knowledge. Based on the findings, students may regard EAP as the English lessons in high school and use the same methods to learn. By this means, more attention is paid to English language learning and some key academic skills might be ignored, such as presentation skills, which results in academic difficulties in undergraduate degree courses. In consequence, the real aim of curriculum design for the first year is expected to be explained clearly to guide learners how to learn.

Secondly, when students enter into the cooperation university, they are exposed to the western education model, which is characterized as student-centered, so more engagement and interactions in class is required. By this means, the foreign pedagogical approaches are imported to China, thus achieving the purpose to conduct TNHE, which is to increase competitiveness of Chinese higher education [19]. Yet not all students adapt to the western approach because they are used to the Chinese teaching styles and the traditional student-teacher relationship. Specifically, there exists a strong hierarchical relationship between students and teachers for tutors are regarded as the authority who impart knowledge [17]. With this deep-rooted concept, Chinese students usually keep quiet in class and seldom question their teachers. Hence, culturally sensitive pedagogical approaches should be adopted, which take into consideration the learner cultural backgrounds. The findings demonstrate that instructors have taken measures to promote teaching efficiency, by selecting students to interact and answer questions in the class. Nevertheless, as for the students, they reported difficulties to different teaching styles. It is suggested that courses introducing western academic cultures should be offered to allow learners to gain comprehensive understanding of the different education system.

As a supportive learning environment is highlighted in the ICD framework [15], teachers and students should cooperate together to better conduct TNHE. Therefore, in addition to teachers' alterations, students need to adjust their learning approaches to a new learning environment. In particular, to adapt to foreign academic cultures, learners' active participation in class and interaction with instructors are required, which may also influence their final grades. When the undergraduate courses begin, teachers would not offer stage-by-stage help and support as the preliminary year. In consequence, the marking criteria might be unclear to learners because of its subjective nature. This corresponds to the findings of [20], who indicated that 
the unfamiliarity with the scoring criteria and expectations confuse Chinese students to a large degree. Hence, without communication with teachers, the grading standards cannot be understood thoroughly, which might then affect student's academic success [21]. It shows the significance of context-specific assessment [15].

\section{CONCLUSION}

This study has examined students' learning perceptions and experiences during the preparation stage in a cooperation university. Nevertheless, it is small-scale, with only six participants from the same joint university, which cannot be generalized to all students learning in this type of institution. Hence, future research can involve more learners from different cooperation universities to examine their teaching and learning experiences in a more specific and comprehensive way. Additionally, how policymakers and teachers comprehend the differences in culture and education between the two systems is also worth exploring.

In general, the preliminary year allows students to experience and gradually adapt to a different education system, from the perspective of curriculum design, teaching and learning approaches, as well as assessment styles. However, the courses are not appropriate to Chinese students, which ignore their prior learning experiences and skills. As a consequence, learners find it challenging to adapt to different teaching styles, which requires them to change their learning approaches and become autonomous learners.

As a result, based on the academic difficulties students have encountered, more needs to be done to improve the design of the foundation year. Firstly, institutions should investigate the differences in culture and education systems among China and the foreign partner's country. Then, the detailed information could be presented to both teachers and students, thus promoting their mutual understanding. In this way, the preparation stage can be used to maximum effect to help students transition into undergraduate courses.

\section{REFERENCES}

[1] State Council of China. (2003). Regulations of the People's Republic of China on transnational higher education. Retrieved from

http://www.crs.jsj.edu.cn/index.php/default/news/in $\operatorname{dex} / 2$

[2] Fang, W. H., \& Wang, S. (2014). Chinese Students' Choice of Transnational Higher Education in a Globalized Higher Education Market. Journal of Studies in International Education, 18(5), 475-494.
[3] Liu, D., Wimpenny, K., DeWinter, A., \& Harrison, P. (2021). Students' perceptions and experiences of teaching and learning in transnational higher education in China: implications of the intercultural dialogue framework. Teaching in Higher Education, $1-19$.

[4] Mok, K. H., \& Han, X. (2016). The rise of transnational higher education and changing educational governance in China. International Journal of Comparative Education and Development, 18(1), 19-39.

[5] Zhang, R. R. (2016). Analysis of major reforms in the mode of cooperation between Chinese and foreign universities since the reform and opening up [in Chinese]. Journal of World Education, 29(1), $57-62$

[6] Guo, Q. Liu, Y. (2021). Analysis on the current situation of talent cultivation in sino-foreign cooperative universities under the background of "double-first-class" [in Chinese]. Heilongjiang Researches on Higher Education, 39(3), 52-58.

[7] Cai, L., He, D., Muhammad, O. A., \& Tu, W. J. (2018). Research on the teaching quality structure of sino-foreign joint university and its inspiration - a survey from XJTLU university. International Journal of Information, Business and Management, 10(3), 178-190.

[8] Sun, K. (2014). On the operating system mode of sino-foreign universities. Chongqing Higher Education Research, 2(1), 89-94.

[9] Ennew, C. T., \&Yang, F. J. (2009). Foreign Universities in China: a case study. European Journal of Education, 44(1), 21-36.

[10] Zhuang, L., \& Tang, A. X. (2012). Sino-UK transnational education in China. Journal of Technology Management in China, 7(2), 218-234.

[11] Wang, Y. X., \& Bai, L. (2021). Academic acculturation in $2+2$ joint programmes: students' perspectives. Higher Education Research and Development, 40(4), 852-867.

[12] Mok, K. H. \& Han, X. (2015). Managing changing labour market needs and 'Brain Drain' problems: a study of motivation of students studying abroad or transnational higher education in China. The International Symposium on Globalization, Changing Labour Market and Social Mobility.

[13] Dai, K., Matthews, K. E. \& Renshaw, P. (2020). Crossing the 'bridges' and navigating the 'learning gaps': Chinese students learning across two systems in a transnational higher education 
program. Higher education research and development, 39(6), 1140-1154.

[14] Lee, H. H., Kim, G. M. L. \& Chan, L. L. 2015. Good Teaching: What Matters to University Students? Asia Pacific Journal of Education, 35 (1), 98-110.

[15] Wang, T. 2016. Intercultural Dialogue Framework for Transnational Teaching and Learning. In Campus Support Services, Programmes, and Policies for International Students, edited by B. Krishna and C. Foster, 223-242. Hershey, PA: IGI Global.

[16] Tang, Q. (2020). Towards integration: the pursuit of concepts in sino-foreign joint ventures of universities [in Chinese]. China Academic Journal Electronic Publishing House, 6, 9-14.

[17] Heffernan, T., Basu, M. P. \& Sweeney, A. (2010). Cultural differences, learning styles and transnational education. Journal of higher education policy and management, 32(1), 27-39.

[18] Creswell, J. W. (2008). Educational research: Planning, conducting, and evaluating quantitative and qualitative research. Upper Saddle River, NJ: Pearson Education.

[19] Huang, F. (2007). Internationalization of higher education in the developing and emerging countries: a focus on transnational higher education in Asia. Journal of Studies in International Education, 11(3-4), 421-432.

[20] Heng, T. T. (2018). Different is not deficient: contradicting stereotypes of Chinese international students in US higher education. Studies in Higher Education, 43(1), 22-36.

[21] Tran, L. T. (2011). Committed, face-value, hybrid or mutual adaptation? The experiences of international students in Australian higher education. Educational Review, 63(1), 79-94. 